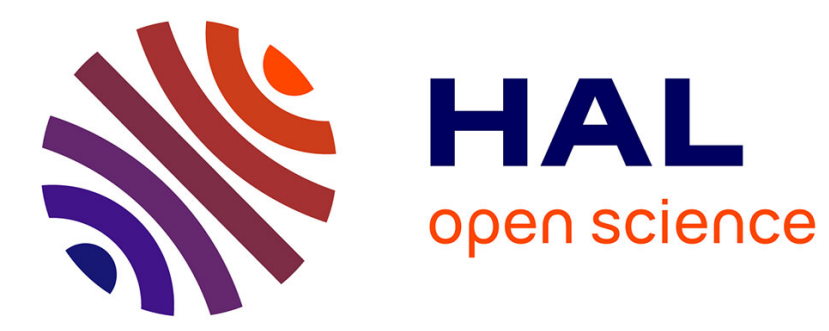

\title{
Mechanical behavior of stiff coating on glass under sliding contact
}

\author{
X. Geng, Zhen Zhang, E. Barthel, D. Dalmas
}

\section{To cite this version:}

X. Geng, Zhen Zhang, E. Barthel, D. Dalmas. Mechanical behavior of stiff coating on glass under sliding contact. Wear, 2010, 269 (5-6), pp.351-361. 10.1016/j.wear.2010.04.016 . hal-00533819

\section{HAL Id: hal-00533819 https://hal.science/hal-00533819}

Submitted on 8 Nov 2010

HAL is a multi-disciplinary open access archive for the deposit and dissemination of scientific research documents, whether they are published or not. The documents may come from teaching and research institutions in France or abroad, or from public or private research centers.
L'archive ouverte pluridisciplinaire HAL, est destinée au dépôt et à la diffusion de documents scientifiques de niveau recherche, publiés ou non, émanant des établissements d'enseignement et de recherche français ou étrangers, des laboratoires publics ou privés. 


\title{
Mechanical behavior of stiff coating on glass under sliding contact
}

\author{
X. Geng ${ }^{\mathrm{a}}$, Z. Zhang ${ }^{\mathrm{b}}$, E. Barthel ${ }^{\mathrm{a}}$, D. Dalmas Ba $^{* a}$ \\ a Unité Mixte CNRS/Saint-Gobain "Surface du Verre et Interfaces" UMR 125, \\ Saint-Gobain Recherche, BP 135, F-93303, Aubervilliers, Cedex, France. \\ ${ }^{b}$ Microsoft, 1085 La Avenida, Mountain View, CA 94043, USA
}

\begin{abstract}
In this paper, we investigate the failure mechanism under scratch testing of glass samples coated with an $\mathrm{Si}_{3} \mathrm{~N}_{4}$ monolayer deposited by magnetron sputtering. We demonstrate that applying a thin $\mathrm{Si}_{3} \mathrm{~N}_{4}$ layer considerably compromises the effective glass strength. Contact and fracture mechanics conspire to produce this result when a stiff and well adherent film is deposited on a more compliant substrate. Three major phenomena have been identified: (i) the $\mathrm{Si}_{3} \mathrm{~N}_{4}$ layer generates a high friction coefficient which enhances the tensile stress at the trailing edge of the contact zone, (ii) the stiff film enhances the in-plane tensile stress due to elastic mismatch and (iii) when a through-thickness crack hits the interface, the elastic mismatch provides a strong driving force for the crack to cross the interface and penetrate into the glass substrate. A specific type of damage, where a hierarchy of cracks is observed in the trail of the indenter instead of the more usual homogeneous series of so-called Hertzian cracks, is also discussed.
\end{abstract}

Key words: Thin film, Scratch testing, Fracture, Sliding friction, Damage mechanism

PACS: 62.20, 46.55.+d, 62.25.+g

\section{Introduction}

Coatings are often deposited on glass substrates to modify their surface properties and impart new functionalities. However, thin films suffer from

\footnotetext{
*Corresponding author

Email address: davy.dalmas@saint-gobain.com (D. Dalmas)
} 
specific mechanical problems such as cracking $[1,2,3,4]$, delamination $[5,6]$, buckling, etc... In many industrial applications the origin of these failures comes from the contact between the thin film and the slider. The failure of a coated system due to a sliding contact is usually investigated by "scratch tests". In a scratch test, a conical or spherical indenter slides over the coating surface under an increasing or a constant normal load $P$ until some well defined failure occurs.

Thus, identification of failure mechanisms during scratch test is of great importance. When thin films are concerned, many different failure modes can be found in the literature, such as plastic deformation, brittle fracture, buckling and spallation, etc. In fact, it is usual that several different failure modes occur at the same time.

Bull $[1,7]$ has classified the failure modes in terms of the hardness of substrate and coating. Generally, soft coatings fail by plastic deformation whether deposited on soft or hard substrates. For hard coatings, the plastic deformation is minimal, but coating fracture or interfacial fracture (debonding) dominate the scratch response.The coating fracture can be partial Hertzian cracking or circular Hertzian cracking due to tensile stresses near the back rim of the contact zone. These cracks initiate within the coating, run across the coating thickness and often arrest at the interface to form the so-called "through-thickness cracks" $[1,2]$. Then the through-thickness cracks usually elongates laterally in the coating to form "channel cracks" which are much longer than the coating thickness [8]. The channel cracks may extend into the substrate or result in interface cracks [9]. Interfacial debonding can induce buckling, which occurs in response to the compressive stresses generated ahead of the moving indenter [10]. Through-thickness cracks appear due to the bending stresses of buckles, either forming a series of conformal cracks in the scratch track or resulting in coating spallation [1].

Of course, this general picture, which relies on the relative hardness of coating and substrate, is actually affected by a large number of parameters, including scratching conditions (e.g., indenter shape, loading rate, scratching speed [11], friction between indenter and coating [12]), substrate properties (e.g., elastic modulus), and coating properties (e.g., modulus, thickness, residual stress). Especially for thin films, interfacial properties (e.g., interfacial toughness, flaw size and distribution) are of primary concern.

Brittle fracture of isotropic and homogeneous solids under a spherical contact load have been studied widely. Starting from Hertz (1882) [13], many researchers such as Roesler (1956) [14], Frank and Lawn (1967) [15], Moug- 
inot and Maugis (1985) [16], Chaudhri and Philips (1990) [17], among many others, investigated the mechanisms for forming cone cracks in homogeneous solids under normal loads. Contact mechanics and linear elastic fracture mechanics were used to predict the conditions necessary to cause fracture and the subsequent depth and shape of the cracks. When a brittle solid is pressed with a spherical indenter, a ring crack at the surface appears just outside the contact rim and propagates away into the solid to form a cone.

The fracture pattern changes if the indenter slides over the surface under combined normal and tangential loads. A periodic array of partial cone cracks forms in the wake of the slider, with an inclination almost perpendicular to the surface $[18,19,20,21,22,23,24,25]$. The cracks are initiated at the trailing edge of the contact, and then propagate both laterally and inside the substrate. In addition, a characteristic spacing between neighboring cracks appears. The tangential load exerted by friction affects both the fracture conditions and the geometry of partial cone cracks.

Once a solid is covered by a coating, both stress fields and fracture behavior are altered. Stress fields in a coated solid for both cylindrical and spherical contacts have been studied extensively, e.g., Barovich et al. (1964) [26], Gupta and Walowit (1974) [27], King and O'Sullivan (1987) [28], Jaffar (1988) [29], among others. These calculations all show that the contact stresses in a coated solid are strongly influenced by the modulus mismatch of the coating and substrate, and by the thickness of the coating. Consequently, the fracture behaviors diversify as coating fracture, substrate fracture and interfacial delamination. For example, Oliveira and Bower (1996) [30] found that the coating fracture is more likely to occur than the interfacial delamination. In terms of coating failure, fracture is sometimes likely to initiate just above the interface rather than from the surface, since the location of the greatest tensile stress can be changed by the modulus mismatch, the friction coefficient and the ratio of contact size to coating thickness. Holmberg et al. [31, 32, 33, 34] used finite element analysis to simulate the stress fields and fracture behavior under various conditions. In these studies, however, the coating thickness is comparable with the contact size.

When the coating is very thin compared with the contact zone, e.g. three orders of magnitudes smaller, some simplifications appear, as we may expect that most of the stress field is correctly described by the half-space solution. To illustrate and analyze this specific case of thin film, the damage mechanisms which occurs during scratch testing of a thin and stiff film deposited on a glass substrate is investigated in this paper. First, the stress field in the 


\begin{tabular}{|c|c|c|c|}
\hline Materials & $\begin{array}{c}\text { Young's modulus } \\
E(\mathrm{GPa})\end{array}$ & $\begin{array}{c}\text { Poisson's ratio } \\
\nu\end{array}$ & $\begin{array}{c}\text { Fracture energy } \\
\Gamma\left(\mathrm{J} / \mathrm{m}^{2}\right)\end{array}$ \\
\hline Steel 100C6 & 200 & 0.27 & - \\
Soda-lime glass & 72 & 0.2 & 9 \\
$\mathrm{Si}_{3} \mathrm{~N}_{4}$ & 310 & 0.22 & $15 \sim 110$ \\
\hline
\end{tabular}

Table 1: Mechanical properties of the materials in the coating-substrate system.

thin coating under a sliding contact is analyzed and an analytical solution from the half space expressions is proposed. Then, the impact of the modulus mismatch and the friction coefficient is discussed explicitly. The results of scratch experiments carried out on a $\mathrm{Si}_{3} \mathrm{~N}_{4}$ monolayer deposited on glass by magnetron sputtering are described. Based on optical and SEM observations, the failure mechanisms are analyzed in terms of crack initiation and propagation. Finally, the observed crack hierarchy and spacing are discussed.

\section{Materials and methods}

\subsection{Tribometer}

Scratch tests were performed with a commercial ball-on-plane tribometer (Plint TE79). The main characteristics of the tribometer are as follows:

- Normal force P: $1 \sim 20 \mathrm{~N}$ applied as a dead load;

- Sliding speed $V: 0.01 \sim 10 \mathrm{~mm} / \mathrm{s}$;

- Sliding length: $1 \sim 20 \mathrm{~mm}$.

The tribometer measures the tangential friction force $Q$ with a lateral force sensor from which the friction coefficient $\mu=Q / P$ is deduced (Fig. 1(a)).

The scratches were carried out with a spherical steel indenter (radius $R=5 \mathrm{~mm}$ ). The mechanical properties of the indenter are found in Tab. 1 . To obtain reproducible measurements, both the indenter and the specimens were cleaned in an ultrasonic cleaner subsequently with detergent solution (Alconox@), distilled water and alcohol, and then dried with compressed nitrogen gas before each test.

Single-pass mode scratch tests were performed with a constant normal load maintained during each pass. This single-pass mode is thought to be 


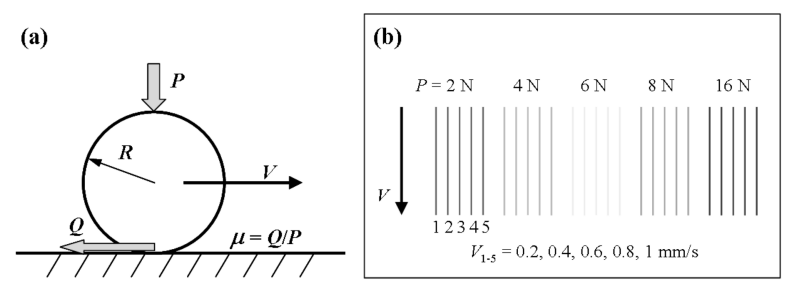

Figure 1: (a) Schematic of ball-on-plane tribometer test. (b) During a tribometer test, a series of 25 scratches were made under a normal load $P$ of $2 \mathrm{~N}, 4 \mathrm{~N}, 6 \mathrm{~N}, 8 \mathrm{~N}$ and $16 \mathrm{~N}$, respectively; the scratching speed $V$ ranging from $0.2 \mathrm{~mm} / \mathrm{s}$ to $1 \mathrm{~mm} / \mathrm{s}$ were tested for each load.

reliable for assessing the failure criterion, since the coating response is integrated over a significant sliding distance. However, this mode requires more experimental work as several scratches must be performed above and below the critical load at which failure occurs to narrow down the "framing interval" [35].

A standard procedure was used to carry out the scratch tests. A series of 25 single-pass scratches were made, as shown in Fig. 1(b). The applied loads $P$ were $2 \mathrm{~N}, 4 \mathrm{~N}, 6 \mathrm{~N}, 8 \mathrm{~N}$ and $16 \mathrm{~N}$, respectively; different scratching speeds ranging from $0.2 \mathrm{~mm} / \mathrm{s}$ to $1 \mathrm{~mm} / \mathrm{s}$ were tested for each load. The length of each scratch is about $10 \mathrm{~mm}$.

All the tests were conducted in open air at ambient temperature. For each sample, at least three series of test were carried out to guarantee the consistency of the obtained results.

\subsection{Sputtered $\mathrm{Si}_{3} \mathrm{~N}_{4}$ thin films}

In the present study, two types of coatings were deposited on soda-lime glass substrates $(2.1 \mathrm{~mm}$ thick) by magnetron sputtering. The first type is a simple $\mathrm{Si}_{3} \mathrm{~N}_{4}$ monolayer with a thickness of $200 \mathrm{~nm}$. In order to study the effect of a significantly lower friction coefficient, a surface treatment was used for the second type of samples. A proprietary lubricative oxide $\left(\mathrm{SnZnO}_{x}\right)$ overcoat ( $4 \mathrm{~nm}$ thick) was deposited by magnetron sputtering on top of the $\mathrm{Si}_{3} \mathrm{~N}_{4}$ layer. The mechanical properties of the substrate and the $\mathrm{Si}_{3} \mathrm{~N}_{4}$ film are found in Tab. 1. For both type of coatings, the surface roughness is slightly higher than for float glass. The RMS roughness evaluated on $1 \times 1 \mu \mathrm{m}^{2} \mathrm{AFM}$ images is less than $2 \mathrm{~nm}$. 


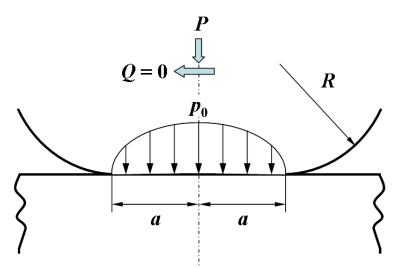

Figure 2: Ball-on-plane problem in Hertzian contact theory.

The $\mathrm{Si}_{3} \mathrm{~N}_{4}$ monolayers were deposited on glass using an Alcatel Lina 350 in-line sputtering system. For lubricated samples, the two layers are deposited in-line, without breaking the vacuum, with a pre-sputter time of $3 \mathrm{~min}$. $\mathrm{Si}_{3} \mathrm{~N}_{4}$ was obtained by reactive sputtering of a polycrystalline Si target using argon and nitrogen as primary sputtering and reactive gases. For all the experimental runs, the background pressure before deposition was about $7 \times 10^{-7}$ mbar and the total sputtering pressure was $8 \times 10^{-3} \mathrm{mbar}$. The cathodic power applied to the targets was $2000 \mathrm{~W}$. For reactive sputtering, nitrogen partial pressures were adapted for a full nitridation of $\mathrm{Si}_{3} \mathrm{~N}_{4}$. All substrates were cleaned by hot demineralized water and mechanical brushing before deposition.

\section{Calculation}

\subsection{Theoretical background}

\subsubsection{Elastic contact}

Starting from Hertz in 1880s [13], the theory of elastic contact mechanics aroused considerable interest and has provided fundamental tools to study the contact and scratch phenomena.

Consider the ball-on-plane contact problem in Fig. 2. The radius of the spherical indenter is $R$, the substrate is semi-infinite, and the radius of the contact area is $a$. Hertz figured out the analytical solution for the pressure distribution in terms of the total normal load and the elastic properties of indenter and substrate, based on the following assumptions:

1. The dimension of the contact area is much smaller than the dimension of the elastic bodies, i.e. $a<<R$.

2. The contact surfaces are frictionless, i.e. $Q=0$. 
Then, the radius of the circular contact $a$ is given by

$$
a=\left[\frac{3}{4} P R\left(\frac{1-\nu_{i}^{2}}{E_{i}}+\frac{1-\nu_{s}^{2}}{E_{s}}\right)\right]^{1 / 3},
$$

where $E$ is Young's modulus and $\nu$ Poisson's ratio. The subscripts $i$ and $s$ refer to the indenter and the substrate, respectively.

The distribution of contact pressure, $p$, is axisymmetric:

$$
p(r)=p_{0} \sqrt{1-(r / a)^{2}},
$$

where $r$ is the radial coordinate, the origin being the center of the contact, and $p_{0}$ is the peak contact pressure at the center given by

$$
p_{0}=\frac{3 P}{2 \pi a^{2}} \text {. }
$$

\subsubsection{Sliding contact on homogeneous solids}

Following Hertz theory on normal contact for frictionless bodies, the first studies of elastic contact under the influence of tangential forces were published by Cattaneo in 1938 [36] and Mindlin in 1949 [37]. They made the assumption that the shear stress due to frictional sliding $q(r)$ on the surface is everywhere proportional to the normal pressure $p(r)$, the constant of proportionality being the same as the coefficient of friction between the bounding solids. That is,

$$
\mu=Q / P=q(r) / p(r)
$$

for the whole contact area $r \leqslant a$.

The Cattaneo-Mindlin friction law was confirmed by experiments [38, 39, 40]. However, Mindlin was mainly interested in the problem of surface compliance and partial slip, and did not investigate the stress field beneath the surface. This was achieved by Hamilton and Goodman in 1966 [41], again with the restriction of a circular area of contact. They gave the equations for the stresses in an implicit form, which involved taking the imaginary parts of a series of complicated algebraic expressions. While this can be done easily enough on a computer it does mean that explicit expressions were not available, which complicated subsequent attempts to study fracture mechanics and plastic shakedown.

Hamilton in 1983 [42] extracted the imaginary parts explicitly and gave the stress distribution of $\sigma_{x}$ on the surface as a function of friction coefficients. 
When the contact surfaces are frictionless, i.e. $\mu=0$, one reverts to the Hertz problem and the stresses are symmetric with respect to the center of contact. By contrast, when friction is considered, the stress distribution is asymmetric. Clearly, friction adds compressive stresses to the leading edge of the contact and intensifies the tensile stresses at the trailing edge. The maximum tensile stress occurs at the trailing edge where $x=-a$.

The stress field in a coated solid under a sliding contact may result from a complex combination of various effects [32]:

1. external loading, e.g., the normal pressure and surface shear between the sliding indenter and the coating surface;

2. internal loading, e.g., the residual stress generated during the coating deposition process or due to the thermal expansion mismatch;

3. mechanical properties of coating and substrate, e.g., Young's modulus, plastic yield strength, fracture toughness, etc.

The impact of a coating in various conditions has been frequently studied in the literature. Since the stress field in the coating/substrate system is very complicated, it is hard to find an analytical solution [43, 44]. Some progress has been made with finite element analysis (FEA) [45, 46, 47] and experimental validation $[48,33]$ particularly in cases where both coating and substrate remain elastic. All these studies show that the contact stresses in a coated solid are strongly influenced by the friction coefficient, the elastic mismatch between coating and substrate, and the ratio of coating thickness to contact radius.

\subsection{Stress field in a thin coating under a sliding contact}

As just shown, the quasistatic stress field around a spherical sliding contact area in an uncoated homogeneous solid is well defined and has been solved analytically by Hamilton and Goodman $(1966,1983)$ [41, 42]. In this paper,the analytical solution for the stress field in a thin coating under a sliding contact will be derived from Hamilton's equation based on the following arguments:

1. Compared with the thickness of glass substrate and the size of the indenter, the $\mathrm{Si}_{3} \mathrm{~N}_{4}$ coating is so thin as to be treated as the skin of the substrate. Therefore, the stresses and strains in the coating are assumed not to vary across the coating thickness. 
2. The coating is well bonded on the glass substrate, and so deforms compatibly with the substrate. Therefore, the in-plane strains in the coating are the same as the in-plane strains in the top surface of substrate.

The derivation begins by defining the Cartesian coordinate $(x, y, z)$ in the thin coating. The coating surface coincides with the coordinate plane $(x, y)$; the direction perpendicular to the surface is the $z$-axis. The sliding direction is pointing to the positive $x$-axis direction. The stress components in the coating, $\sigma_{x x}^{f}, \sigma_{y y}^{f}, \tau_{x y}^{f}$ are in the $x-y$ plane. The pressure $p$ and shear traction $q$ are applied by the indenter on the top surface of the coating. Correspondingly, the reactive pressure $p$ and shear traction $q$ are applied by substrate with equal magnitudes but opposite directions on its bottom surface.

Accepting the simplification introduced by Hertz (1882) [13], Cattaneo (1938) and Mindlin (1949) [37], the pressure $p$ is given by Eq. 2 and frictional traction $q$ in the contact zone $r \leq a$ is:

$$
q=\mu p_{0} \sqrt{1-(r / a)^{2}}
$$

where $r=\sqrt{x^{2}+y^{2}} ; a$ the radius of contact zone; $\mu$ the friction coefficient between steel indenter and $\mathrm{Si}_{3} \mathrm{~N}_{4}$ coating; and $p_{0}=3 P /\left(2 \pi a^{2}\right)$ the peak Hertzian pressure at the center of contact under the normal load $P$.

The contact zone is completely determined by the indenter and substrate, regardless of the coating effect [49]. Hence, the radius of the contact zone, $a$, is given by Hertz theory (Eq. 1).

The stresses in the surface of substrate were explicitly given by Hamilton (1983) [42]. When inside the contact $r \leq a$ and $z=0$, the stress components in the substrate, $\sigma_{x x}^{s}, \sigma_{y y}^{s}$, and $\tau_{x y}^{s}$, are of relatively simple formula:

$$
\begin{aligned}
\sigma_{x x}^{s}= & \frac{p_{0}}{a}\left[\frac { 1 } { r ^ { 2 } } \left\{\frac{y^{2}-x^{2}}{r^{2}}\left[\frac{1-2 \nu_{s}}{3}\left\{\left(a^{2}-r^{2}\right)^{3 / 2}-a^{3}\right\}\right]\right.\right. \\
& \left.\left.-\left(x^{2}+2 \nu_{s} y^{2}\right)\left(a^{2}-r^{2}\right)^{1 / 2}\right\}-\mu \frac{\pi x}{2}\left(\frac{\nu_{s}}{4}+1\right)\right] \\
\sigma_{y y}^{s}= & \frac{p_{0}}{a}\left[\frac { 1 } { r ^ { 2 } } \left\{\frac{x^{2}-y^{2}}{r^{2}}\left[\frac{1-2 \nu_{s}}{3}\left\{\left(a^{2}-r^{2}\right)^{3 / 2}-a^{3}\right\}\right]\right.\right. \\
& \left.\left.-\left(y^{2}+2 \nu_{s} x^{2}\right)\left(a^{2}-r^{2}\right)^{1 / 2}\right\}-\mu \frac{3 \pi \nu_{s} x}{8}\right]
\end{aligned}
$$




$$
\begin{aligned}
\tau_{x y}^{s}= & \frac{p_{0}}{a}\left[\frac{x y\left(1-2 \nu_{s}\right)}{r^{4}}\left\{-r^{2}\left(a^{2}-r^{2}\right)^{1 / 2}-\frac{2}{3}\left(a^{2}-r^{2}\right)^{3 / 2}+\frac{2}{3} a^{3}\right\}\right. \\
& \left.+\mu \frac{\pi y}{4}\left(\frac{\nu_{s}}{2}-1\right)\right]
\end{aligned}
$$

For the solutions outside the contact and the variation in $z$ direction, please refer to Hamilton (1983) [42].

By applying Hooke's law and the following compatibility equations:

$$
\varepsilon_{x x}^{s}=\varepsilon_{x x}^{f}, \quad \varepsilon_{y y}^{s}=\varepsilon_{y y}^{f}, \quad \varepsilon_{x y}^{s}=\varepsilon_{x y}^{f}
$$

then, the in-plane stresses in the coating are given as follows:

$$
\begin{gathered}
\sigma_{x x}^{f}=\frac{E_{f}}{E_{s}}\left(\frac{1-\nu_{f} \nu_{s}}{1-\nu_{f}^{2}} \sigma_{x x}^{s}+\frac{\nu_{f}-\nu_{s}}{1-\nu_{f}^{2}} \sigma_{y y}^{s}\right)+\frac{p \nu_{s}}{1-\nu_{f}}\left(\frac{E_{f}}{E_{s}}-\frac{\nu_{f}}{\nu_{s}}\right) \\
\sigma_{y y}^{f}=\frac{E_{f}}{E_{s}}\left(\frac{1-\nu_{f} \nu_{s}}{1-\nu_{f}^{2}} \sigma_{y y}^{s}+\frac{\nu_{f}-\nu_{s}}{1-\nu_{f}^{2}} \sigma_{x x}^{s}\right)+\frac{p \nu_{s}}{1-\nu_{f}}\left(\frac{E_{f}}{E_{s}}-\frac{\nu_{f}}{\nu_{s}}\right) \\
\tau_{x y}^{f}=\frac{E_{f}}{E_{s}} \frac{1+\nu_{s}}{1+\nu_{f}} \tau_{x y}^{s}
\end{gathered}
$$

where $E$ and $\nu$ are Young's modulus and Poisson's ratio; subscript or superscript $f$ and $s$ refer to coating and substrate.

As for the out-of-plane stress components, $\sigma_{z z}^{f}, \tau_{x z}^{f}$ and $\tau_{y z}^{f}$, are directly obtained based on argument 1. That is,

$$
\sigma_{z z}^{f}=-p, \quad \tau_{z x}^{f}=q, \quad \tau_{z y}^{f}=0
$$

As noted by Hamilton (1983) [42], the maximum tensile stress in the substrate is at the trailing edge, i.e., $x=-a$ and $y=z=0$, with magnitude as follows:

$$
\sigma_{\max }^{s}=p_{0}\left[\frac{1-2 \nu_{s}}{3}+\mu \cdot \frac{\pi\left(4+\nu_{s}\right)}{8}\right]
$$

Similarly, the maximum tensile stress in the coating is also at the trailing edge with magnitude:

$$
\sigma_{\max }^{f}=p_{0} \frac{E_{f}}{E_{s}} \frac{1+\nu_{s}}{1+\nu_{f}}\left[\frac{1-2 \nu_{s}}{3}+\mu \cdot \frac{\pi\left(4-3 \nu_{s}-\nu_{f} \nu_{s}\right)}{8\left(1-\nu_{f}\right)}\right]
$$




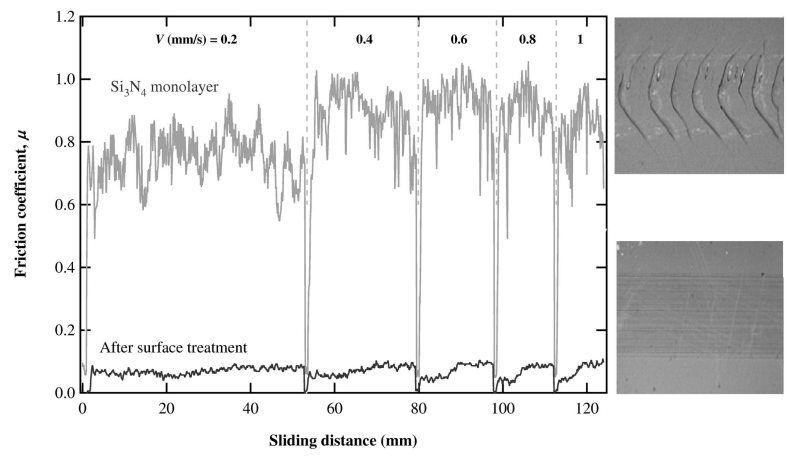

Figure 3: Typical curves of friction coefficient with a normal load of $2 \mathrm{~N}$ versus sliding distance for the five scratching speeds $V$ in the range of 0.2 to $1 \mathrm{~mm} / \mathrm{s}$ and the associated optical images of scratch track for the $\mathrm{Si}_{3} \mathrm{~N}_{4}$ monolayer without (top) and with (bottom) surface treatment.

In order to evaluate the fracture initiation, the in-plane first principal stress $\sigma_{1}$ in the surface of the thin coating is given by the following equation:

$$
\sigma_{1}=\frac{1}{2}\left[\left(\sigma_{x x}^{f}+\sigma_{y y}^{f}\right)+\sqrt{\left(\sigma_{x x}^{f}-\sigma_{y y}^{f}\right)^{2}+4\left(\tau_{x y}^{f}\right)^{2}}\right]
$$

\section{4. results}

\subsection{Intrinsic friction coefficient - scratch}

To understand the scratch process, we want to characterize the intrinsic friction coefficient between coating surface and indenter. The friction coefficient $\mu$ was measured with the tribometer as a function of normal load $P$ and scratching speed $V$. Typical curves of $\mu$ versus sliding distance for the $\mathrm{Si}_{3} \mathrm{~N}_{4}$ monolayer with and without surface treatment, integrated with the corresponding typical optical images of scratch tracks, are shown in Fig. 3. In this figure, only the measurements for the first 5 scratches under $P=2 \mathrm{~N}$ with a scratching speed $V$ of $0.2,0.4,0.6,0.8$ and $1 \mathrm{~mm} / \mathrm{s}$, respectively, are presented.

For the $\mathrm{Si}_{3} \mathrm{~N}_{4}$ monolayer coatings, the curve of friction coefficient fluctuates remarkably, which is related to the presence of a series of cracks (top image in Fig. 3). The friction coefficient of the $\mathrm{Si}_{3} \mathrm{~N}_{4}$ monolayer coatings reaches $0.9 \pm 0.39$. It is not an intrinsic friction coefficient which is recorded 


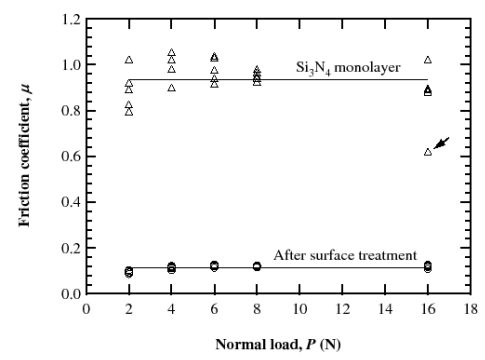

Figure 4: Mean friction coefficient $\mu$ versus normal load $P$ for $\mathrm{Si}_{3} \mathrm{~N}_{4}$ monolayer with and without lubricative surface treatment. At each load, the five points correspond to the mean friction coefficient measured for the five scratching speeds $V$ in the range of 0.2 to $1 \mathrm{~mm} / \mathrm{s}$.

but only an effective one. The type of damage observed on Fig. 3 for the $\mathrm{Si}_{3} \mathrm{~N}_{4}$ monolayer will be discussed below in detail. Nevertheless, we will assume that this type of damage does not significantly affect the friction coefficient. Therefore, we take the friction coefficient of the $\mathrm{Si}_{3} \mathrm{~N}_{4}$ monolayer as $\mu=0.9$. To avoid such scratch damage, one must reduce the applied pressure $p$, either by reducing the normal load $P(<2 \mathrm{~N})$ or by increasing the radius of the indenter $R$ ( $>5 \mathrm{~mm})$. However, none of them is feasible due to the measurement limitations of the tribometer.

For the second type of specimen with lubricative surface treatment, the friction coefficient falls down to $0.1 \pm 0.02$. In most cases, no visible damage or just very superficial damage were observed (bottom image in Fig. 3). Scratch failure rarely and randomly appeared when a higher load was applied which was probably due to some defects in the coating or a third body under the contact.

The statistical results of all the tests are summarized in Fig. 4. The friction coefficient $\mu$ is plotted as a function of normal load $P$. For one coating system, five data are plotted at each normal load, corresponding to average values of five scratching speeds $(0.2,0.4,0.6,0.8$ and $1 \mathrm{~mm} / \mathrm{s})$, respectively. As expected, $\mu$ is affected neither by $P$ nor by $V$.

\subsection{Scratch tests: multiple hertzian cracking}

A single $\mathrm{Si}_{3} \mathrm{~N}_{4}$ layer, with thickness $200 \mathrm{~nm}$, was deposited on a glass substrate and scratched by a spherical steel indenter with a radius of $5 \mathrm{~mm}$. The applied normal loads were $2 \mathrm{~N}, 4 \mathrm{~N}, 8 \mathrm{~N}$ and $16 \mathrm{~N}$ respectively. To observe 

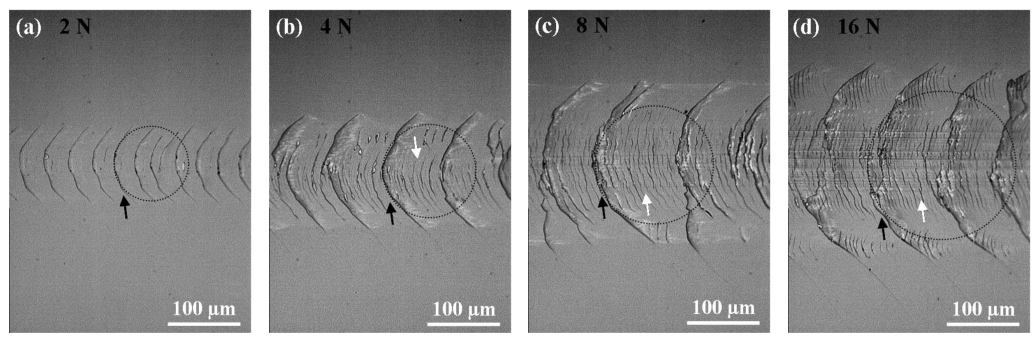

Figure 5: Optical top views of multiple Hertzian cracks in the $\mathrm{Si}_{3} \mathrm{~N}_{4}$ monolayer coated glass after scratching by a spherical steel indenter. The applied normal load is (a) $2 \mathrm{~N}$, (b) $4 \mathrm{~N}$, (c) $8 \mathrm{~N}$ and (d) $16 \mathrm{~N}$, respectively. The black circle represents the boundary of the contact zone. The "primary cracks" that extend outside the contact area are pointed by black arrows; the "secondary cracks" between the primary cracks are pointed by white arrow. The scratching direction is from left to right.

damages and understand their origin, optical and SEM observations of the scratch track and section were performed.

To evaluate the effect of the coating and respectively of lowering the friction coefficient, bare glass substrates and lubricated $\mathrm{Si}_{3} \mathrm{~N}_{4}$ coated samples were scratched under the same loading conditions. In most cases, no damage were observed neither for bare glass or lubricated samples. These two important results will be discussed in next section.

\subsubsection{Top views of scratch track}

The top views of crack patterns on $\mathrm{Si}_{3} \mathrm{~N}_{4}$ /glass after scratching, observed by optical microscopy, are displayed in Fig. 5. For the respective load values, the expected diameters of the contact zones (depicted by black circles on the figure) were $100 \mu \mathrm{m}, 130 \mu \mathrm{m}, 160 \mu \mathrm{m}$ and $205 \mu \mathrm{m}$, as derived from Eq.(1).

When $2 \mathrm{~N}$ is applied, a series of evenly spaced Hertzian cracks is left in the scratch track (Fig. 5(a)). The cracks, which extend outside the contact area, are designated as "primary cracks" and denoted by a black arrow. As the load increases to $4 \mathrm{~N}$, the primary cracks grow longer along with the contact zone and have a larger interval (Fig. 5(b)). Besides, several fine cracks appear between the primary ones and seem to be confined within the contact. Since these cracks initiate at higher loads, they are designated as "secondary cracks", and pointed by a white arrow. When the load doubles from $4 \mathrm{~N}$ to $8 \mathrm{~N}$, the secondary cracks become denser and longer, but are 

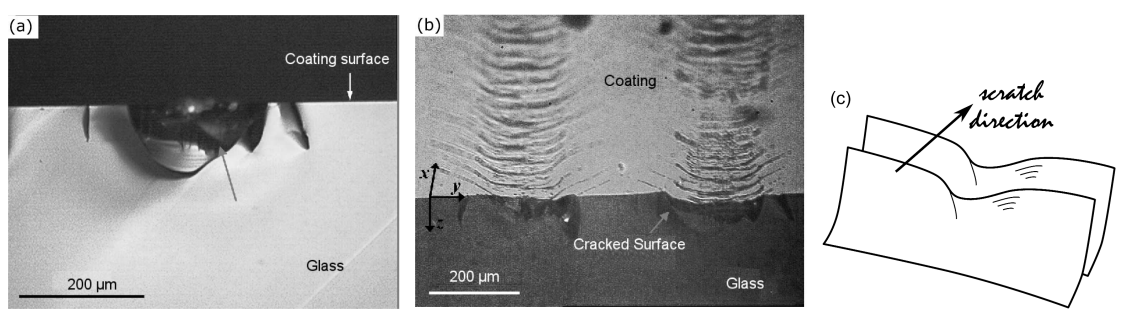

Figure 6: (a) Transverse cross section ( $y$ - $z$ plane) optical images of a scratch at $16 \mathrm{~N}$ performed on a $\mathrm{Si}_{3} \mathrm{~N}_{4}$ monolayer ( $200 \mathrm{~nm}$ thick) coated glass sample. The scratch is along the $x$-axis direction.(b) Transverse cross section view with a tilt angle of about $10^{\circ}$ around the $y$ axis. (c) Schematics of inverted Hertzian cracks in $\mathrm{Si}_{3} \mathrm{~N}_{4}$ monolayer coated glass.

still confined within the contact (Fig. 5(c)). The primary and the secondary cracks keep growing as the load increases up to $16 \mathrm{~N}$ (Fig. 5(d)).

The dependence of the primary crack spacing upon the applied normal load $P$ can be observed on Fig. 5. It jumps up by a factor of about 3 as $P$ increases from $2 \mathrm{~N}$ to $4 \mathrm{~N}$. Subsequently, at higher loads, it increases slightly. The average spacing of the primary cracks normalized by the contact radius as a function of normal load is summarized in Fig. 14 and will be discussed in Section 5.3.2.

\subsubsection{Cross section views of scratch track}

Some samples were cut along the scratch track direction or normal to it and the cross sections were observed by optical microscopy and SEM.

In Fig. 6, optical images of the transverse cross section of a scratch at $16 \mathrm{~N}$ for the $\mathrm{Si}_{3} \mathrm{~N}_{4}$ coated sample are displayed. The primary cracks are clearly identified and their shape in Fig. 6(a) are very similar to the Hertzian cone crack under indentation [50]. The secondary cracks cannot be clearly identified due to the cutting damage and low magnification. As expected, the primary cracks penetrate through the coating/substrate interface deep into the glass substrate(see Fig. 6(a)). The penetration depth of the primary cracks is approximately $70 \mu \mathrm{m}$. Moreover on Fig. 6(b), on which a cross section of a tilted sample is displayed, the simultaneous view of the top surface allows to better observe the extension of the primary crack outside the contact area. The cracked surface appears in relief in the contact area and is an inverted conical surface (Fig. 6(c)). 

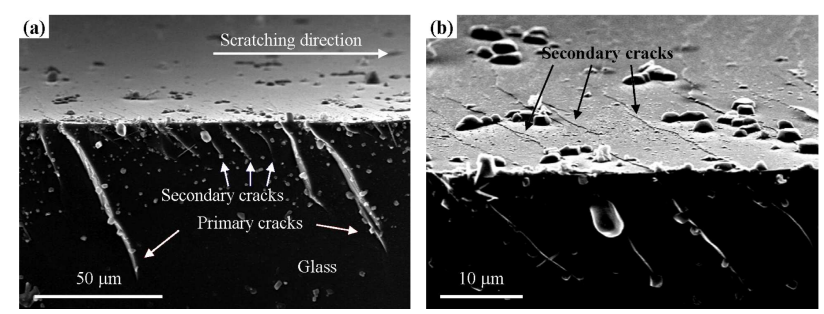

Figure 7: Longitudinal cross section ( $x-z$ plane) SEM images at two magnification of a scratch at $6 \mathrm{~N}$ performed on a $\mathrm{Si}_{3} \mathrm{~N}_{4}$ monolayer (200 nm thick) coated glass sample. The sample is tilted at an angle of about $10^{\circ}$ around the $x$ axis. (a) Both the primary and the secondary Hertzian cracks penetrate in the glass substrate.(b) Detailed view of the secondary cracks.

In Fig. 7, SEM images of the longitudinal cross section of a scratch at $6 \mathrm{~N}$ for the $\mathrm{Si}_{3} \mathrm{~N}_{4}$ coated sample are displayed. Both the primary cracks and the secondary cracks in between are identified. As for the primary ones, the secondary cracks are not confined to the $\mathrm{Si}_{3} \mathrm{~N}_{4}$ coating but do penetrate deep into the glass substrate with a smaller depth of around $15 \mu \mathrm{m}$. The inclination of these two types of cracks is very similar with an angle of about $60^{\circ}$ to the surface toward the scratch direction.

\subsubsection{Irreversible elastic deformation}

The surface details of the crack trail has also been investigated by SEM. On Fig. 8, the morphologies of both primary and secondary cracks is observable on the tilted surface of the sample. As the two cracked surfaces did not perfectly recover after the indenter has slide away, a permanent step of about $160 \mathrm{~nm}$ in height for the primary crack is observable and can also be measured by AFM (Fig. 8(c)). For the secondary cracks (Fig. 8(b)), the recovery is also not perfect but the height of the residual step is significantly smaller (some nanometers). The protruding surface inclines towards the sliding direction (Fig. 8(a)), which is in accordance with the inclination in Fig. 7.

The origin of this residual deformation is linked to the evolution of the stress distribution at the trailing edge of the contact (see section3.2). $\mathrm{Si}_{3} \mathrm{~N}_{4}$ and glass, belonging to typical brittle materials, are expected to deform purely elastically. So no plasticity effect can be the origin of such permanent step. Nevertheless, as the indenter slides away from the crack, the external force is expected to gradually withdrawn until null which is actually 

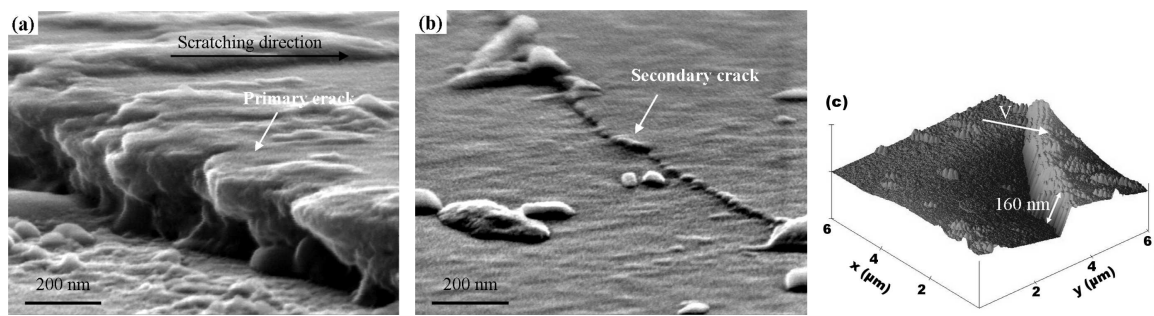

Figure 8: Surface SEM images of a scratch performed on a $\mathrm{Si}_{3} \mathrm{~N}_{4}$ monolayer (200 nm thick) coated glass sample. The morphology of the primary crack (a) and the secondary crack (b) after scratching shows an imperfect permanent recovery. The residual step height in the middle region of a primary crack can be measured by AFM (c).

the case in absence of cracks. But in our case, as the indenter is sliding over the coating surface, the primary crack initiates at the trailing edge of the contact and propagates. Thus during unloading, the presence of the new free surfaces (i.e: the two crack surfaces) modify the stress field at the rear of the contact zone and the deformation of the surface is different for each side of the cracks. The rear side of the crack is unloaded first and start touching the other side before this last one is fully unloaded. Static friction then partly locks the surfaces, leading to this irreversible elastic deformation of the cracked material.

\section{Discussion : Analysis of failure mechanisms}

As just shown in previous section, the scratch failure morphologies for the $\mathrm{Si}_{3} \mathrm{~N}_{4}$ coated glass are very similar to what has been already observed on uncoated soda-lime glass [50]. Indeed a scratch leaves behind a trail of periodic (partial) hertzian cracks. However, the presence of a tough and stiff thin film with a good adhesion, such as $\mathrm{Si}_{3} \mathrm{~N}_{4}$, has notable effects on the process especially concerning the minimum load that is required to initiate such failure mechanism. For example, in the present study, no cracks were observed during scratching of bare glass specimen even for the highest load we used $(16 \mathrm{~N})$ whereas $\mathrm{Si}_{3} \mathrm{~N}_{4}$ coated specimen were already damaged for the lowest one $(2 \mathrm{~N})$. This dramatic reduction of the scratch resistance can be explained as we will see in this section by two successive effects. First, crack initiation is facilitate by the enhancement of the surface stresses and second, 

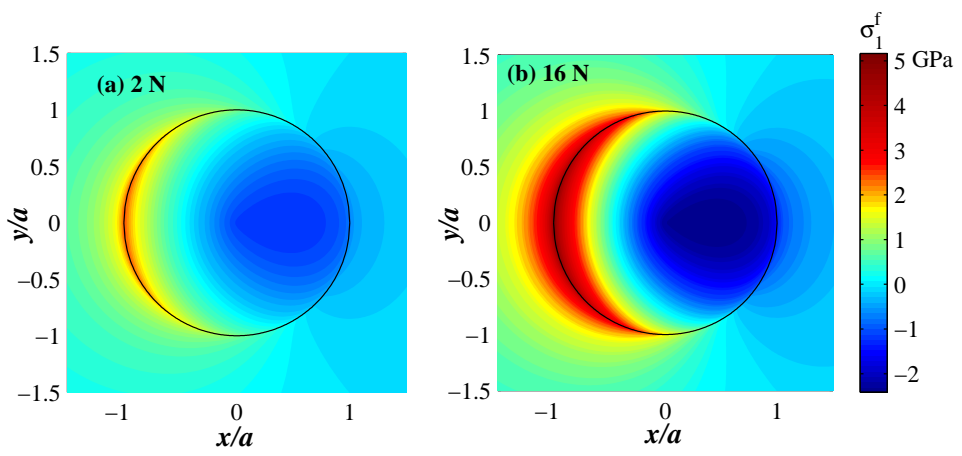

Figure 9: Spatial distribution of in-plane first principal stress in $\mathrm{Si}_{3} \mathrm{~N}_{4}$ coating (Eq. 16) within and around the contact zone (black circle). The indenter slides in the $x$ direction, and $\mu=0.9$. The applied normal load are (a) $2 \mathrm{~N}$ and (b) $16 \mathrm{~N}$.

unstable crack propagation in the substrate occurs.

Before proceeding, let us also note that the stress distribution under a sliding contact scales in a very simple manner. When the load increases, all spatial coordinates scale with the contact radius while all stresses scale with $p_{0}$ (Section 3.2). For example, the spacial distribution of the in-plane first principal stress $\sigma_{1}^{f}$ (Eq. 16) in the $\mathrm{Si}_{3} \mathrm{~N}_{4}$ coating $(\mu=0.9)$ is plotted in Fig. 9 for the two extremal normal loads in this study $P=2 N$ and $16 \mathrm{~N}$. All the lengths are normalized by the radius of contact $a$, but the stresses remain as absolute values. Obviously, the spatial distribution between compressive and tensile regions does not vary with $P$. However, the magnitude naturally increases with increasing normal load. In this figure, the dark circle represents the boundary of the contact zone and the indenter slides in the $x$ direction from left to right. The stress level is displayed with a rainbow spectrum; blue colors correspond to compressive regions and red to tensile regions.

\subsection{Crack initiation by enhancement of surface stresses}

For any materials, the energy release rate of a surface flaw with size $l$, i.e the driving force for crack to propagate, is:

$$
G \sim \frac{\sigma_{s}^{2} l}{\bar{E}_{s}}
$$

Therefore, a crack will propagate if this energy release rate reaches the fracture energy (equivalent to the toughness) of the material. It means that at a 

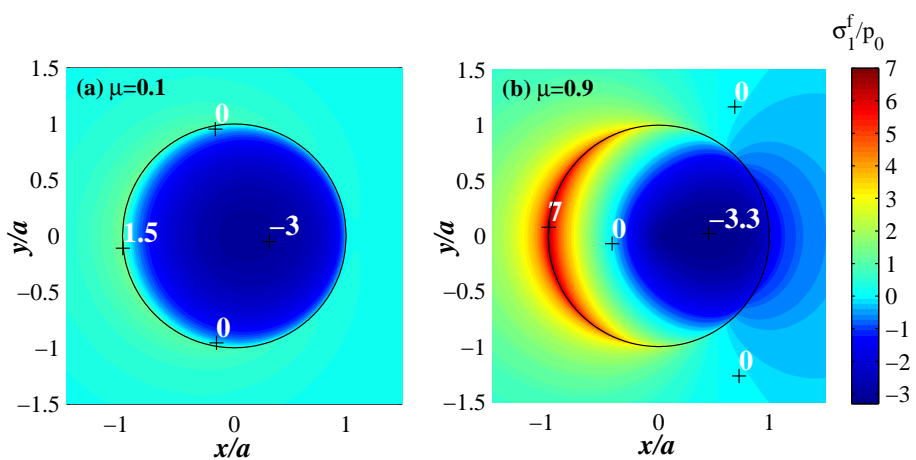

Figure 10: Spatial distribution of in-plane first principal stress $\sigma_{1}$ (Eq. 16) in the $\mathrm{Si}_{3} \mathrm{~N}_{4}$ coating within and around the contact zone (black circle) for coatings with $(\mu=0.1)$ and without $(\mu=0.9)$ the lubricative surface treatment. The stresses are normalized by the peak Hertzian pressure $p_{0}$. The indenter slides in the $x$ direction.

given load, the surface flaws must have a minimum size and at a given flaw size, the stresses have to be sufficiently high.

In our $\mathrm{Si}_{3} \mathrm{~N}_{4}$ coated glass specimens, we have shown that Hertzian cracks initiate at the trailing edge of the contact, where the maximum tensile stress at the coating surface $\sigma_{\max }^{f}$ is located. Thus, the main driving force $G$ for crack initiation depends on the value of $\sigma_{\max }^{f}$ which is a function of the peak pressure $p_{0}$, the friction coefficient and the modulus mismatch (see. Eq. 15). From this classical fracture initiation analysis, it is obvious that crack initiation is more likely to occur at higher loads. However, the effect of the two other parameters is less trivial and will be discussed in the following.

\subsubsection{Effect of friction coefficient}

To demonstrate the effect of the friction coefficient, the distribution of the calculated in-plane fist principle stress $\sigma_{1}$ in the $\mathrm{Si}_{3} \mathrm{~N}_{4}$ coating (Eq. 16) is plotted in Fig. 10 for coatings with $(\mu=0.1)$ and without $(\mu=0.9)$ the lubricative surface treatment. In these plots, the stresses are normalized by the peak Hertzian pressure $p_{0}$ and all the lengths are normalized by the radius of the contact zone $a$.

As for bulk materials [42], the increase of friction coefficient redistributes the stress field at the surface of a coating. For low friction (Fig. 10(a)), nearly all the contact zone is under compression. Very little tension appears at the trailing edge. When the friction coefficient increases to a value as 
high as 0.9 (Fig. 10(b)), the distribution of $\sigma_{1}$ becomes heavily skewed: the compressive region shrinks to the front part of the contact; the tensile region develops from the trailing edge to the rear part. In addition, the friction has a significant effect on the magnitude of the tensile stress, which is scaled up from $1.5 p_{0}$ to $7 p_{0}$ when $\mu$ goes from 0.1 to 0.9 . In term of energy release rate (Eq. 17), it means scaling up by a factor of about 20 . So, the lubricative specimen have much less chances to cracked in the same loading conditions than the $\mathrm{Si}_{3} \mathrm{~N}_{4}$ monolayer. Therefore, the lowering of the friction coefficient is the main reason for the absence of damage observed on lubricated specimens.

\subsubsection{Effect of modulus mismatch}

Besides the exact solutions given in Eq. 10 and Eq. 12, the effect of the modulus mismatch between coating and substrate on stress distribution in a sliding contact can be investigated in a simpler manner by looking at scaling effects. Due to the continuity of the tangential displacements, the in-plane stresses in the thin coating are roughly scaled (up or down) by a factor equal to the modulus ratio, i.e.:

$$
\sigma_{\alpha}^{f} \approx \sigma_{\alpha}^{s} \cdot E_{f} / E_{s} \quad \text { with } \alpha=x x, y y \text { or } x y
$$

This result suggests that for a given normal load, the presence of a stiff thin coating compared to his substrate intensifies the in-plane stresses at the surface.

Take the current coated system as an example: the Young's modulus of $\mathrm{Si}_{3} \mathrm{~N}_{4}$ is $310 \mathrm{GPa}$ and that of soda-lime glass is $72 \mathrm{GPa}$ (see. Table 1). Thus, the stresses in the surface of coated glass with $\mathrm{Si}_{3} \mathrm{~N}_{4}$ layer are roughly scaled up by a factor of 4.3, compared with uncoated glass.

From previous analysis, we have seen that high friction coefficient also intensified the tensile stress at the surface. On a glass substrate, the presence of a $\mathrm{Si}_{3} \mathrm{~N}_{4}$ coating not only generates a high elastic mismatch but also increases the friction coefficient from 0.2 (between steel indenter and glass) up to 0.9 (between steel indenter and $\mathrm{Si}_{3} \mathrm{~N}_{4}$ ). Therefore, the tensile stress at the coating surface is considerably enhanced due to the combination of the two effects. As a result, the maximum in-plane tensile stress at the surface for a steel/glass contact under a $2 \mathrm{~N}$ normal load is $\sigma_{1}^{f} \simeq 200 \mathrm{MPa}$ while it climbs up to $\sigma_{1}^{f} \simeq 3 \mathrm{GPa}$ for the $\mathrm{Si}_{3} \mathrm{~N}_{4}$ coated glass. Inserted in Eq. 17, the impact of the coating is a gain of more than two orders of magnitude, provided the flaw size $l$ stays constant. This consideration explains why a 


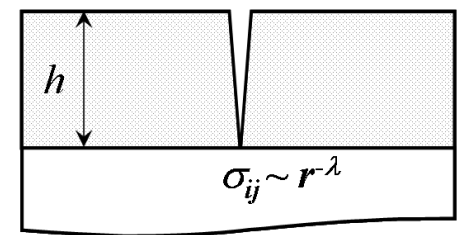

(a)

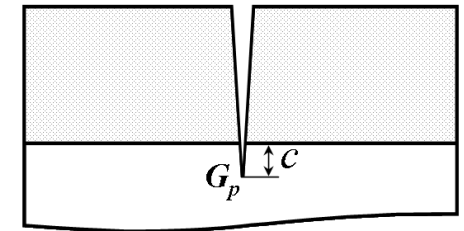

(b)

Figure 11: (a) A through-thickness crack intersecting the $\mathrm{Si}_{3} \mathrm{~N}_{4}$ coating/glass substrate interface; (b) penetrating crack in the substrate.

$2 \mathrm{~N}$ load is enough to induce a trail of hertzian cracks on a $\mathrm{Si}_{3} \mathrm{~N}_{4}$ coated glass even if for bulk materials $\mathrm{Si}_{3} \mathrm{~N}_{4}$ fracture energy or toughness is higher (see Table 1). Indeed the fracture energy ratio between $\mathrm{Si}_{3} \mathrm{~N}_{4}$ and glass is of the order of 10 whereas their energy release rate ratio is of the order of 200 .

\subsection{Unstable crack penetration into the substrate}

After initiation in the thin coating, the crack meets the interface (Fig. 11). As observed in the previous experiments, the crack penetrates into the glass substrate.

Consider a through-thickness crack sitting on the interface, as in Fig.11(a). The stress field around the crack tip is singular:

$$
\sigma_{i j} \sim r^{-\lambda}
$$

where $\lambda \in(0,1)$ is the singularity exponent [51]. The value of $\lambda$ depends on the modulus mismatch. If the materials of the coating and substrate have identical elastic properties, $\lambda$ is equal to $1 / 2$, i.e. we recover the well-known square-root singularity.

If there is a small penetrating flaw of size $c$ as in Fig. 11(b), the energy release rate at the penetrating crack tip scales as [52]:

$$
G_{p} \sim \frac{\sigma_{1}^{2} h}{\bar{E}_{f}}\left(\frac{c}{h}\right)^{1-2 \lambda}
$$

When the condition [53]:

$$
\frac{E_{f}}{E_{s}} \cdot \frac{\left(1+\nu_{s}\right)\left(3-4 \nu_{s}\right)}{\left(1+\nu_{f}\right)\left(3-4 \nu_{f}\right)}<1
$$


is satisfied, the singularity exponent $\lambda$ value is less than $1 / 2$, and the energy release rate $G_{p}$ goes to zero if the penetrating flaw size is infinitesimally small. Thus, in the case of a compliant coating on stiff substrate, the energy release rate of penetrating crack starts from zero. Hence, a minimum flaw size in the substrate is required. Otherwise, the penetration in the substrate will be shielded.

Conversely, if the inequality in Eq.(21) is reversed, the singularity exponent $\lambda$ becomes higher than $1 / 2$ and $G_{p}$ goes to infinity when the flaw size $c$ goes to zero. This is actually the case in the current system $\mathrm{Si}_{3} \mathrm{~N}_{4} /$ glass where $\mathrm{Si}_{3} \mathrm{~N}_{4}$ is stiffer than glass. Therefore once a surface crack in the $\mathrm{Si}_{3} \mathrm{~N}_{4}$ coating is initiated, the crack penetrates across the interface and propagates into the glass substrate unstably to a certain depth, at which the energy release rate drops below the fracture toughness of glass. Cracks in the coating acts as a flaw for the substrate and renucleation is not necessary. It is expected that this effect, combined with the stress enhacement due to modulus mismatch and friction, is also very effective for the reduction of the scratch resistance for coated specimen with thin stiff materials.

\subsection{Crack propagation}

Beyond the general idea that a stiff adhesive film will enhance the sensitivity to scratching, we would like to better understand the cracking process. This requires predictions of the observed crack paths and the crack size hierarchy. However, both depend on the stress field inside or at the surface of the solid after cracking has occurred, an obviously difficult issue.

\subsubsection{Crack path}

For the prediction of the crack path, the issue of the stress field in the cracked solid has often been successfully circumvented by neglecting the impact of the cracks on the stress field. This is the traditional method to study the crack path in homogenous solids under spherical sliding contact $[18,19,20,21,34]$. Because it is expected that the crack propagation follows pure mode-I, to an excellent first approximation [18], the cracking is expected to proceed orthogonally to the first principal tensile stress ${ }^{1} \sigma_{1}^{s}$, thus following a surface delineated by the trajectories of the other two principal stresses $\sigma_{2}^{s}$ and $\sigma_{3}^{s}$. For example, Fig. 12 plots the stress trajectories of the

\footnotetext{
${ }^{1}$ We take the usual convention that the three principal stresses in glass substrate are denoted by $\sigma_{1}^{s}, \sigma_{2}^{s}, \sigma_{3}^{s}$ and $\sigma_{1}^{s} \geq \sigma_{2}^{s} \geq \sigma_{3}^{s}$.
} 


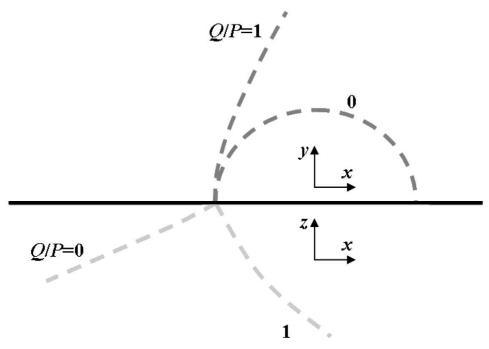

Figure 12: Stress trajectories of the second and third principal stresses $(\mu=Q / P=0$ and 1.0, broken lines). Above the horizontal black line is half-surface view, and below the line is side view. The dark gray broken line is the stress trajectory of the second principal stress starting from the middle point of trailing edge. The light gray broken line is the stress trajectory of the third principal stress.

second and third principal stresses [22, 24]. Above the horizontal black line is the top view of the half surface, and below the line is the side view. The dark grey broken line is the stress trajectory of $\sigma_{2}^{s}$, starting from the middle point of trailing edge. The light grey broken line is the stress trajectory of $\sigma_{3}^{s}$. When a crack proceeds from the middle point of the trailing edge, the $\sigma_{2}^{s}$ trajectory carries the crack forwards laterally, and the $\sigma_{3}^{s}$ trajectory carries the crack downwards with an inclination angle.

The inclination angle of the crack with the surface depends on the friction coefficient, i.e., the ratio of shear to normal load, $\mu=Q / P$, as depicted by the schematics in Fig. $12[22,24]$. If there is no friction, i.e. $Q / P=$ 0 , the ring crack forms (dark grey broken line) and propagates downwards with an inclination backwards (light grey broken line), and finally a cone crack forms [15]. When $Q / P$ increases, the partial cone crack forms with an inclination angle varying from backwards to forwards. In our case, for $Q / P=0.9$, the inclination angle is approximately $60^{\circ}[22,23]$. This estimate is completely consistent with the crack inclination observed on the cross sections (Fig. 7).

\subsubsection{Crack spacing and hierarchy}

Crack spacing results from the elastic interactions between cracks. Understanding the spacing requires to calculate crack paths from the stress field of the cracked material. This phenomenon has been studied in details for 
homogenous solids [21, 22, 24]. In their 2D model, Bower and Fleck [22] modeled the crack as a line distribution of dislocations superposed on the contact displacement field. For crack propagation they also adopted the criterion that the crack front is opened purely by local tensile stress $\sigma_{1}^{s}$ at the crack front and they proposed the following scratch generation mechanism (Fig.13(a)). Assume a dense distribution of surface flaws (Fig.13(a-1)). a first crack propagates at the trailing edge of the indenter (Fig.13(a-2)). The stress field around the slider is significantly altered by the presence of this first crack: the tensile stresses are substantially reduced. If a second surface flaw is close to the crack, it will not propagate (Fig.13(a-3)): it is shielded and growth is inhibited. A new crack will be generated after the indenter moves forward beyond a critical spacing (Fig.13(a-4)). In the end, the scratch leaves a trail of evenly spaced partial cone cracks (Fig.5(a)). Bower and Fleck [22] have shown that the spacing, normalized to the contact size, is a monotonically decreasing function of the applied load. The spacing is much larger than the contact zone when the applied load is close to the critical load and decreases rapidly when the load increases.

In this paper, when the load is relatively low, a single series of regularly spaced primary cracks is observed (Fig. 5(a)) in complete agreement with the Bower and Fleck model. However, at higher loads, a series of secondary cracks appears between the primary cracks (Fig.5). This hierarchy of Hertzian cracks has seldom been reported [54]. In our case, the secondary cracks do penetrate into the substrate (Fig. 7) but are shorter than the primary cracks. A second specific feature in our system is that the spacing of the primary cracks as a function of load is not monotonic (Fig. 14) which is in contradiction with the behavior predicted for a homogeneous half-space [22]. We note that the normalized crack spacing starts to increase when the secondary cracks appear. An obvious interpretation is that the secondary cracks relax a fraction of the in-plane tensile stress, resulting in larger spacing between the primary cracks. The non monotonic behavior for the spacing is simply triggered by the impact of the secondary cracks on the surface in-plane tensile stress. Moreover, the presence of the $\mathrm{Si}_{3} \mathrm{~N}_{4}$ coating, which facilitates crack nucleation, has an impact on the crack size distribution. Roughly speaking, the $\mathrm{Si}_{3} \mathrm{~N}_{4}$ coating will allow cracks to propagate where no crack would appear in the absence of coating. But this mechanism will be confined to regions close to the surface as argued previously (Section 5.2).

Taking into account of all these observations, Fig.13(b) gives a qualitative explanation for the crack hierarchy. After a through-thickness crack close to 


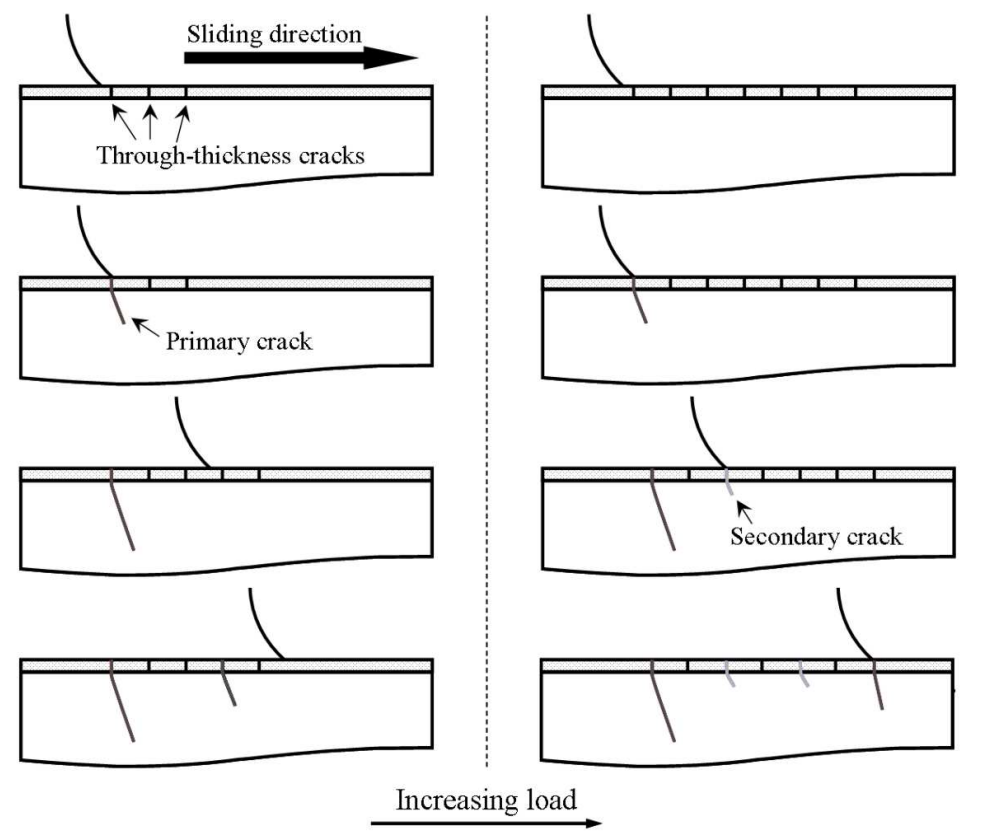

(a)

(b)

Figure 13: The fracture hierarchy of Hertzian cracks. (a) Only primary cracks form in the track of scratch when a relatively low load is applied; (b) secondary cracks form between the primary ones if the load becomes high.

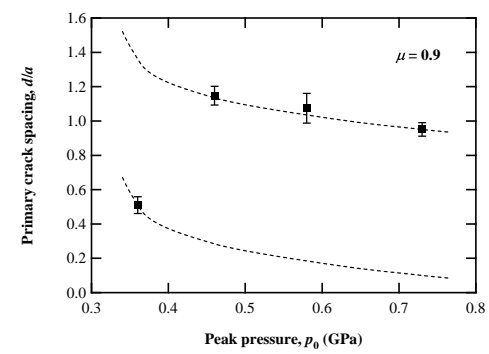

Figure 14: Spacing of the primary cracks normalized by contact radius, $d / a$, is plotted as a function of peak pressure $p_{0}$. The dash lines are drawn schematically according to Bower and Fleck (1994). 
trailing edge has formed a primary crack (Fig.13(b-2)), the tensile stress near the primary crack is significantly reduced. However, due to the presence of the $\mathrm{Si}_{3} \mathrm{~N}_{4}$ coating, and when the load is large enough, other surface flaws propagate into the glass substrate to a smaller depth, forming a secondary crack (Fig.13(b-3)). As the slider passes, a number of secondary cracks form. However, as the slider moves away from the primary crack, the impact of the primary crack decreases and the conditions are such that a new primary crack, with a deeper penetration into the substrate, can be formed (Fig.13(b4)), a process analogous to the original mechanism [21] (Fig.13(a-4)).

\section{Conclusion}

In this paper, we have studied the failure mechanism of a $\mathrm{Si}_{3} \mathrm{~N}_{4}$ coating on glass undergoing scratch testing by a spherical steel indenter. As usual with elastic and brittle materials the failure starts from cracking at the trailing edge of the contact zone, followed by the unstable penetration across the interface with continuous deepening and widening propagation into the glass substrate, finally forming a partial cone crack, with crack depth and width comparable to the contact zone.

However, compared with a homogeneous glass specimen, the $\mathrm{Si}_{3} \mathrm{~N}_{4}$-coated glass is more susceptible to cracking for two mains reasons. First the larger friction coefficient enhances the in-plane tensile stresses which cause the rupture. Second, the modulus of $\mathrm{Si}_{3} \mathrm{~N}_{4}$ is much higher than glass. The stress level in the $\mathrm{Si}_{3} \mathrm{~N}_{4}$ coating is further magnified (here by a factor of 4.3) by this elastic mismatch. This phenomenon makes it easier for flaws in the coating to grow into through-thickness cracks. Furthermore, these through-thickness cracks readily penetrate into the glass substrate. Indeed a crack propagating in a stiffer material and approaching a more compliant one is in an unstable configuration. Crossing the interface does not require any minimum flaw size in the glass substrate (i.e. any renucleation), in contrast to the cases of homogeneous glass or compliant coatings.

Once a partial cone crack is present, the stresses nearby are released. Therefore, a new crack will form after the indenter slides forward beyond a critical spacing. In the end, the scratch leaves a trace of evenly spaced partial cone cracks. This standard scenario has been found to be valid at low loads. At higher loads, our experiments show that a hierarchy of partial cone cracks forms. The primary cracks observe a larger spacing compared to the low load case, which is unexpected. The appearance of secondary cracks 
is ascribed to the impact of the coating which facilitates crack propagation close to the surface. However, the secondary cracks relax a fraction of the in-plane tensile stresses resulting in the anomalous load dependence of the primary crack spacing.

\section{Acknowledgements}

The authors would like to thanks A. Lelarge and L. Cardinal for technical help and SEM images. We also acknowledge J.D. Kamminga, R. Gy and V. Reymond for useful discussion an comments. We acknowledge funding from French ANR through Grant No.MATETPRO07-24714J.

\section{References}

[1] S. Bull, Failure mode maps in the thin film scratch adhesion test, Tribol. Int. 30 (1997) 491-498.

[2] A. Strawbridge, H. Evans, Mechanical failure of thin brittle coatings, Eng. Fail. Anal. 2 (1995) 85-103.

[3] D. Dalmas, S. Benmedakhene, C. Richard, A. Laksimi, G. Béranger, T. Grégoire, Characterization of adherence and cracking within coated materials by an acoustic emission method: application to a wc-co coating on a steel substrate., Comptes Rendus de l'Acadmie des Sciences - Series IIC - Chemistry 4 (5) (2001) 345 - 350.

[4] D. Dalmas, S. Benmedhakne, H. Kebir, C. Richard, A. Laksimi, J. M. Roleandt, Investigation of failure mechanisms in wc-co coated materials, Surf. Coat. Technol. 173 (2-3) (2003) 130 - 143.

[5] E. Barthel, O. Kerjan, P. Nael, N. Nadaud, Asymmetric silver to oxide adhesion in multilayers deposited on glass by sputtering, Thin Solid Films 473 (2005) 272-277.

[6] D. Dalmas, E. Barthel, D. Vandembroucq, Crack front pinning by design in planar heterogeneous interfaces, J. Mech. Phys. Solids 57 (2009) 446457.

[7] S. Bull, E. Berasetegui, An overview of the potential of quantitative coating adhesion measurement by scratch testing, Tribol. Int. 39 (2006) 99-114. 
[8] J. Hutchinson, Z. Suo, Mixed mode cracking in layered materials, Adv. Appl. Mech. 29 (1992) 63-191.

[9] T. Ye, Z. Suo, A. Evans, Thin film cracking and the roles of substrate and interface, Int. J. Solids Struct. 29 (1992) 2639-2648.

[10] A. Evans, J. Hutchinson, On the mechanics of delamination and spalling in compressed films, Int. J. Solids Struct. 20 (1984) 455-466.

[11] C. Gauthier, S. Lafaye, R. Schirrer, Elastic recovery of a scratch in a polymeric surface: experiments and analysis, Tribol. Int. 34 (2001) 469479 .

[12] M. Blees, G. Winkelman, A. Balkenende, J. den Toonder, The effect of friction on scratch adhesion testing: application to a sol-gel coating on polypropylene, Thin Solid Films 359 (2000) 1-13.

[13] H. Hertz, On the contact of elastic solids, J. Reine Angew. Math. 92 (1882) 156-171.

[14] F. Roesler, Brittle fractures near equilibrium, Proc. Phys. Soc. Lond. B 69 (1956) 981-1012.

[15] F. Frank, B. Lawn, On the theory of hertzian fracture, Proc. Roy. Soc. 299 (1993) 291-306.

[16] R. Mouginot, D. Maugis, Fracture indentation beneath flat and spherical punches, J. Mater. Sci. 20 (1985) 4354-4376.

[17] M. Chaudhri, M. Phillips, Quasi-static indentation cracking of thermally tempered soda-lime glass with spherical and Vickers indenters, Philos. Mag. A62 (1990) 1-27.

[18] B. Lawn, Partial cone crack formation in a brittle material loaded with a sliding spherical indenter, Proc. Roy. Soc. Lond. 299 (1967) 307-316.

[19] B. Bethune, The surface cracking of glassy polymers under a sliding spherical indenter, J. Mater. Sci. 11 (1976) 199-205.

[20] L. Keer, R. Worden, A qualitative model to describe the microchipping wear mode in ceramic rollers, Tribal. Trans. 33 (1990) 411-417. 
[21] L. Keer, C. Kuo, Cracking in a loaded brittle elastic half-space, Int. J. Solids Struct. 29 (1992) 1819-1826.

[22] A. Bower, N. Fleck, Brittle fracture under a sliding line contact, J. Mech. Phys. Solids 42 (1994) 1375-1396.

[23] K. Shah, T. Wong, Fracturing at contact surfaces subjected to normal and tangential loads, Int. J. Rock Mech. Min. Sci. 34 (1997) 727-739.

[24] A. Carpinteri, B. Chiaia, S. Invernizzi, Numerical analysis of indentation fracture in quasi-brittle materials, Eng. Fract. Mech. 71 (2004) 567-577.

[25] K. Holmberg, A. Laukkanen, H. Ronkainen, K. Wallin, Tribological analysis of fracture conditions in ultrathin surface coatings by 3D FEM modelling and stress simulations, Tribol. Int. 38 (2006) 1035-1049.

[26] D. Barovich, S. Kingsley, T. Ku, Stresses on a thin strip or slab with different elastic properties from that of the substrate due to elliptically distributed load, Int. J. Eng. Sci. 2 (1964) 253-268.

[27] P. Gupta, J. Walowit, Contact stress between an elastic cylinder and a layered elastic solid, ASME J. Lubr. Technol. 94 (1974) 250-257.

[28] R. King, T. O'Sullivan, Sliding contact stresses in a two-dimensional layered elastic half-space, Int. J. Solids Struct. 23 (1987) 581-597.

[29] M. Jaffar, A numerical solution for axisymmetric contact problems involving indenters on elastic layers, J. Mech. Phys. Solids 36 (1988) 401416.

[30] S. Oliveira, A. Bower, An analysis of fracture and delamination in thin coatings subjected to contact loading, Wear 198 (1996) 15-32.

[31] K. Holmberg, A. Laukkanen, H. Ronkainen, K. Wallin, S. Varjus, A model for stresses, crack generation and fracture toughness calculation in scratched TiN-coated steel surfaces, Wear 254 (2003) 278-291.

[32] K. Holmberg, A. Laukkanen, H. Ronkainen, K. Wallin, S. Varjus, J. Koskinen, Tribological contact analysis of a rigid ball sliding on a hard coated surface. Part I. Modelling stresses and strains, Surf. Coat. Technol. 200 (2006) 3793-3809. 
[33] K. Holmberg, A. Laukkanen, H. Ronkainen, K. Wallin, S. Varjus, J. Koskinen, Tribological contact analysis of a rigid ball sliding on a hard coated surface. Part II. Material deformations, influence of coating thickness and Young's modulus, Surf. Coat. Technol. 200 (2006) 38103823 .

[34] A. Laukkanen, K. Holmberg, J. Koskinen, H. Ronkainen, K. Wallin, S. Varjus, Tribological contact analysis of a rigid ball sliding on a hard coated surface. Part III. Fracture toughness calculation and influence of residual stresses, Surf. Coat. Technol. 200 (2006) 3824-3844.

[35] R. Consiglio, N. Durand, K. Badawi, P. Macquart, F. Lerbet, M. Assoul, J. von Stebut, Mechanical strength assessment of very thin films for optical and electronical applications, Surf. Coat. Technol. 97 (1997) 192.

[36] M. Cattaneo, Sur une forme de lequation de la chaleur eliminant le paradoxe dune propagation instantanee, Comptes Rendus Hebd. Seances Acad. Sci. 247 (1958) 431-433.

[37] R. Mindlin, Compliance of elastic bodies in contact, J. Appl. Mech. 16 (1949) 259-268.

[38] R. Mindlin, W. Mason, I. Osmer, H. Dereziewicz, Effects of an oscillating tangential force on the contact surfaces of elastic spheres, Proceedings of the First U.S. Congress of Applied Mechanics (1952) 203-208.

[39] K. Johnson, Surface interaction between elastically loaded bodies under tangential forces, Proc. Roy. Soc. Lond. A230 (1955) 531-548.

[40] K. Johnson, Contact Mechanics, Cambridge Univ. Press, Cambridge, 1987.

[41] G. Hamilton, L. Goodman, The stress field created by a circular sliding contact, J. Appl. Mech. (1966) 371-376.

[42] G. Hamilton, Explicit equations for the stresses beneath a sliding spherical contact, Proc Instn Mech Engrs 197C (1983) 53-59.

[43] A. Perriot, E. Barthel, Elastic contact to a coated half-space: effective elastic modulus and real penetration, J. Mater. Res. 19 (2004) 600-608. 
[44] C. Fretigny, A. Chateauminois, Solution for the elastic field in a layered medium under axisymmetric contact loading, J. Phys. D: Appl. Phys. 40 (2007) 54185426.

[45] S. van der Zwaag, J. Field, The effect of thin hard coatings on the hertzian stress, Philos. Mag. 46 (1982) 133-150.

[46] H. Djabella, R. Arnell, Finite element analysis of the contact stresses in an elastic coating on an elastic substrate, Thin Solid Films 213 (1992) 205-219.

[47] R. K. Njiwa, R. Consiglio, J. von Stebut, Boundary element modelling of coated materials in static and sliding ball-flat elastic contact, Surf. Coat. Technol. 102 (1998) 148-153.

[48] L. Anderson, I. Collins, Plane strain stress distributions in discrete and blended coated solids under normal and sliding contact, Wear 185 (1995) 23-33.

[49] D. Green, Hertzian contact of coated glass, Glass Technol. 41 (2000) $48-54$.

[50] B. Lawn, M. Swain, Microfracture beneath point indentations in brittle solids, J. Mater. Sci. 10 (1975) 113C22.

[51] A. Zak, M. William, Crack point singularities at a bimaterial interface, J. Appl. Mech. 30 (1963) 142-143.

[52] M. He, J. Hutchinson, Crack deflection at an interface between dissimilar elastic materials, Int. J. Solids Struct. 25 (1989) 1053-1067.

[53] B. Nuller, M. Ryvkin, A. Chudnovsky, A closed-form solution for a crack approaching an interface, J. Mech. Mater. Struct. 1 (2006) 1405.

[54] Y. Wang, S. Hsu, P. Jones, Evaluation of thermally-sprayed ceramic coatings using a novel ball-on-inclined plane scratch method, Wear 218 (1998) 96-102. 